Organschaft

Die Zeitschrift ist amtliches Organ der Bundesanstalt für Materialforschung und -prüfung sowie Organ des Normenausschusses Materialprufung im DIN

\section{Herausgeber}

BAM Bundesanstalt für Materialforschung und -prüfung DGZfP Deutsche Gesellschaft für Zerstörungsfreie Prüfung

DVM Deutscher Verband für Materialforschung und -prüfung

VDI-Gesellschaft Werkstofftechnik

\section{Aufsatz-Redaktion Berlin}

Dr.-Ing. Dietmar Aurich, Ltd. Dir. u.

Prof. (verantwortlich)

Dr. Manfred P. Hentschel

Dr. Jürgen Sickfeld

BAM, Unter den Eichen 87

D-12205 Berlin

Telefon: 0 30/8104-0

Telefax: 030/8104-1107

\section{Redaktion München}

Dipl.-Ing. Angelika Espinosa

Redaktionsassistentin:

Maria Akhavan-Hezavei

Carl Hanser Verlag

Kolbergerstraße 22

D-81679 München

Telefon: 0 89/9 9830-614

Telefax: 0 89/9 9830-623

Beiträge und Mitteilungen für den redaktionellen Inhalt sind an die Redaktion München zu senden. Fachaufsätze (Originalbeiträge) an die Aufsatzredaktion Berlin.

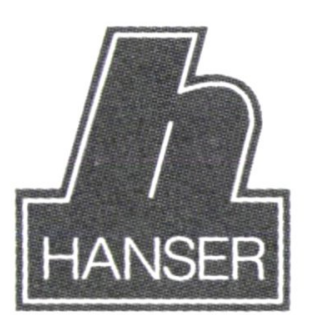

Carl Hanser Verlag

Postfach 8604 20, D-81631 München Telefon (0 89) $99830-0$

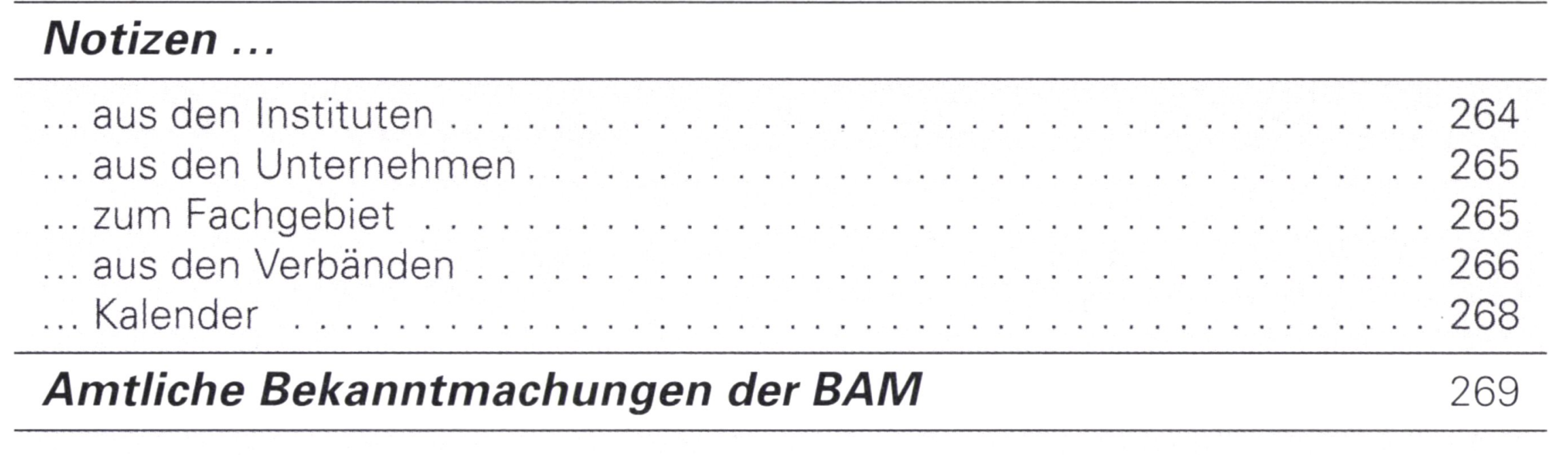

\section{Fachaufsätze}

K. Breitkreutz: Tiefenschärfe rechnerisch verbessern . . . . . . . . . . . . 272

D. Radaj, A. Giering: Spot-Welded H-Specimen . . . . . . . . . . . . . . . . 275

R. Gaus, M. Dienz, K. K. O. Bär: Temperaturmessung und Kalibrierung bis $1800^{\circ} \mathrm{C}$

R. Dahme, A. Fischer: Röntgenprüfung beim Dienstleister . . . . . . . . 286

E. Backer: Anwendersoftware für Ermüdungs- und Bruchmechanikuntersuchungen

W. Andrä, K.-H. Geier, R. Hergt, J. Taubert: Magnetooptik für die Materialcharakterisierung

J. Schuster, K. Friedrich: Thermographie des Schadensverlaufs bei polymeren Verbundproben

K.-W. Harbich, T. Rabe, U. Mücke, A. Lange: Charakterisieren von Poren in Sinterglaskeramik . . . . . . . . . . . . . . . . . . . . . . . . . . 303

F. Bergner, M. Haubold, J. Hünecke: Ultraschallmikroskopie . . . . . . . . 306

\section{Kurzberichte}

SPC in der zerstörungsfreien Werkstoffprüfung . . . . . . . . . . . . 274

Stahlrohre optisch messen ............ 285

Heiße Messung . . . . . . . . . . . . . . . . . . . . . . . . . . . . . . . . . . 297

Dauerschwingversuche mit Luft . . . . . . . . . . . . . . . . . . . . . . . . 301

Echoamplituden reproduzierbar bewerten . . . . . . . . . . . . . . . . . 302

Baukastensystem für die Baustoffprüfung . . . . . . . . . . . . . . . 302

Elektromagnetische Schichtdickenmessung ... . . . . . . . . . . 305

Normen und Richtlinien 310

$\begin{array}{ll}\text { Bücher } & 312\end{array}$

Report 313

Impressum 316

\title{
Der Titelheld
}

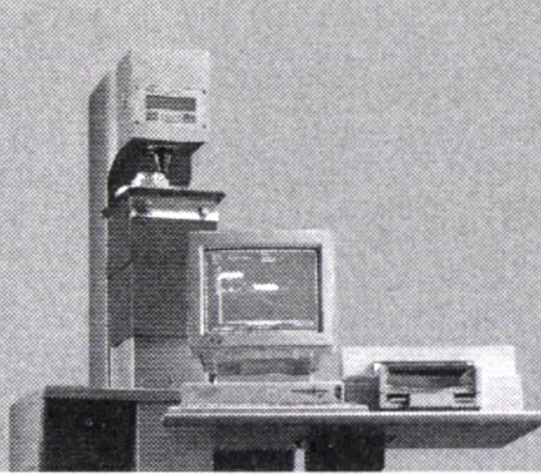

Wer etwas Besonderes leistet, der kommt auch auf die Titelseite einer Zeitschrift. Das war schon immer so. - Statt durch zeitaufwendiges Zersägen ermitteln Sie mit dem neuen M4-EHT Prüfsystem den EHT-Wert eines Werkstücks innerhalb von einer Minute. Daneben bietet das M4-EHT eine Protokollfunktion, Dokumentation des Meßwertes und die Möglichkeit zur Integration in jedes Regelsystem. Selbstverständlich ist das M4-EHT auch für alle gängigen Rockwell-Verfahren geeignet. Wir meinen, das sind die besten Voraussetzungen, um berühmt zu werden.

HAHN \& KOLB Werkzeuge GmbH . Abteilung FA 3 . Borsigstr. 50 - 70469 Stuttgart . Telefon 0711/98 13-442 . Telefax 0711/98 13-731 EMCO MAIER Gesellschaft m.b.H. P. O. Box 131 · Friedmann-Maier-Str. 9 - A-5400 Hallein · Telefon 062 45/891-0 · Telefax 062 45/86965

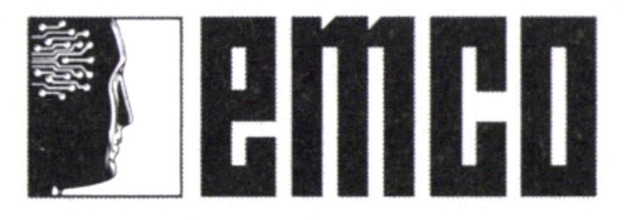

Technologien. Einfach. Gut. 